\title{
Indications for Feature Detection with the Lateral Line Organ in Fish
}

\author{
Horst M. Müller \\ Universität Bielefeld, FAKUltät für Biologie, \\ Lehrstuhl für Neurophysiologie, Postfach 100131, 33501 Bielefeld, Germany
}

\begin{abstract}
Stimulated by a moving object or two stationary, oscillating spheres at different positions to the fish, extracellular recordings were obtained from 77 units in the torus semicircularis of a catfish (Ancistrus spp.). 2. Five mechanosensory units showed complex filter properties, e.g. they responded exclusively to complex hydrodynamic stimuli caused by the moving object, but not to oscillating spheres independent of location, amplitude and phase. 3. Particular midbrain units reacted only to certain stimulus features and responded I) only to the visible vortices following the moving object with a latency of about 300,900 or $2800 \mathrm{~ms}$ depending on the speed of the moving object $(\mathrm{n}=8)$; II) only to a preferred direction of object motion $(\mathrm{n}=12)$; III) only to an exclusively contralateral sphere stimulus, not to a simultaneously bilateral stimulation $(n=3)$. 4 . Seven units have shown a long-lasting response to the moving object $(2.3,10$ and $20 \mathrm{~cm} / \mathrm{sec})$ with one or two zones of inhibition, which reminds one of OFF- or ON-center units in the visual system. 5. The present findings let us assume the existence of filter properties of toral neurons in lareral line processing, which calls to mind "feature detectors" reported in other sensory systems. It can be regarded as evidence for complex perception of the hydrodynamic environment in fish. COMP віоснем PHYsiol. 114A;3:257-263, 1996.
\end{abstract}

KEY WORDS. Catfish, Ancistrus spp., lateral line, torus semicircularis, midbrain, mechanoreception, hydrodynamic sensory systems, feature detection

\section{INTRODUCTION}

An organism's perceptual world is influenced critically by the nature and the fidelity of its sensory systems as these constitute the basis for any mental representation of its environment. Which sense is most vital differs from organism to organism. Our conceptions of a sensory system are usually connected to perceptions in modalities familiar to us, such as vision, audition or olfaction. Because humans have these senses, it is easy to imagine an animal's perception of the environment with these same modalities-even if the fidelity of their sensory organs differs considerably from ours. However, it is very difficult to imagine the bat's representation of its environment via echolocation (31) or that of weakly electric fish via electrical field analysis (7). An extraordinary but lesser known sensory system is the mechanosensory lateral line organ in fish and some amphibians that enables the detection of minute water movements in the immediate environment. Dijkgraaf (12) described this sensory system as "distant-touch sense" ("Ferntastsinn") and Platt, Popper and Fay (30) proposed the verb "sven" for the assumed perception of this unique sense.

\footnotetext{
Address reprint requests to: Horst M. Müller, Universität Bielefeld, Fakultät für Linguistik und Literaturwissenschaft, AG Experimentelle Neurolinguistik, Postfach 100131, 33501 Bielefeld, Germany. Tel. +49-521-1066928; Fax +49-521-106-2996; e-mail: mueller@cogsci.ucsd.edu

Received 26 April 1995; revised 3 August 1995 and 21 November 1995; accepted 21 November 1995.
}

The lateral line consists of a set of individual neuromasts on the surface of fish; each neuromast comprises up to several hundred mechanosensory hair cells, which register water movements. The cilia of the hair cells, protected by a gelatinous cupula, may extend 50 microns into the surrounding water. Neuromasts can occur in isolation (freestanding neuromasts) or in recessed groups that form a canal system with several branches over the head and the body (canal neuromasts). The lateral, often pigmented rows of canal pores that give the organ its name are clearly visible in many species of fish $(3,10)$.

Except for few studies $(6,26)$, the lateral line of a midwater bony fish has been examined exclusively with artificial stimuli consisting of stationary fixed, oscillating spheres (dipole) that elicit a predictable sinusoidal movement in the medium. Earlier studies have yielded results about the physiology of hair cells and their afferent connections $(5,11,14,17,23,27)$ or medullary units $(35)$. While sinusoidal stimuli are well suited for characterizing the peripheral sensory cell with regard to its absolute threshold and its transmission behavior, they tell us little about the role of the lateral line in discriminating the kind of complex highamplitude stimuli that are typical of the natural habitat, where fish usually sense spatially complex water movements, often against a background of high-velocity flow. The present study differs from previous work not only in concentrating on central nervous processing but also by em- 
ploying more ecologically valid stimuli in the form of moving objects. The goal was the use of a complex hydrodynamic stimulus, which shows at least a few similarities to a hydrodynamic event comparable to swimming or a startle response of a fish nearby.

\section{MATERIALS AND METHODS}

Ancistrus spp. (Loricariidae, Siluriformes), a bottom-dwelling catfish from the Amazon, were obtained from a commercial dealer (Glaser, Rottgau) and kept in $200 \mathrm{l}$ aquaria at $26 \pm 2^{\circ} \mathrm{C}$ at a $12-12 \mathrm{hr}$ light-dark cycle daily. Thirty-nine aninuals of both sexes, measuring about $12 \mathrm{~cm}$ in length, were used. After surgery and exposing the midbrain for electrode placement under anesthetic (tricaine methanesulfonate immersion, $1: 15,000$ ) the fish were anesthetized locally with $10 \%$ aqueous lidocaine hydrochloride solution (Xylocaine, Asta), immobilized with $0.1 \mu \mathrm{g} / \mathrm{g}$ body weight pancuronium bromide (Organon-Teknika) and perfused through the mouth with running water $(70 \mathrm{ml} / \mathrm{min})$. To reduce stimulation by surface waves, the fish body was completely submerged. The electrodes reached the brain via a short plastic cylinder glued to the head. To produce more natural, complex hydrodynamic stimuli than sinusoidal vibrations, a rod $(14 \times 8 \mathrm{~mm})$ that extended $1 \mathrm{~cm}$ into the water was moved along a defined circular course $(\varnothing=160$ $\mathrm{mm}$ ) (Fig. 1A). To compare the responses to this novel stimulus with responses to those previously used to excite the lateral line, two oscillating spheres $(\varnothing=6.3 \mathrm{~mm})$, generating sinusoidal vibrations were positioned on each side of the fish in a 15 -mm distance. The two oscillating spheres were mounted on micro manipulators that allowed a variable position parallel to the length body axis of the fish. To create stimulus intensities comparable to the moving object the amplitude of the oscillating spheres could be varied up to $10 \mathrm{~mm}$. Indium-filled glass microelectrodes (19) were used to record extracellularly from lateral line neurons in torus semicircularis. A battery of stimuli was used to identify the different modalities (25). Testing lateral line input: water jet, water movement of a falling drop (with latency); electrosensory tests: moving DC-ficld with 500-700 $\mu \mathrm{V}$ / $\mathrm{cm}$, moving steel needle; auditory tests: sound of a falling drop (without latency), airconducted noise like sinusoidal tones $(50-15,000 \mathrm{~Hz})$, pink noise, speech, or hand clapping; optical tests: diffuse light, moving light bulb in darkness; tactile tests: water jet, touching with a glass fiber $(\phi=125$ $\mu \mathrm{m})$ and a tuft of hairs; vestibulary test: tapping on the tank or ground.

The rod stimulus moving at either $2.3 \mathrm{~cm}$, or 10 or 20 $\mathrm{cm} / \mathrm{sec}$ generated repeated water movement along the body of the fish. It was driven by a DC-motor equipped with a transmission, operated in three speeds. On its circular course, and when the rod was next to the fish, the transient water movement reached maximum intensity every $2.5,5$ and 22 seconds for $20 \mathrm{~cm} / \mathrm{sec}, 10 \mathrm{~cm} / \mathrm{sec}$, and $2.3 \mathrm{~cm} / \mathrm{sec}$ stimuli, respectively. Due to the mechanical circumstances, the movement of the rod was neither linear nor was the created water movement uniform. However, especially the slight non-linearity in the movement of the rod and the randomized vortices are responsible for this kind of complex stimulus. The stimulus is defined only as complex water movement caused by a continuously moved rod in the water next to the fish. Other than using oscillating spheres, these complex stimuli induced by a moving rod are very difficult to control in an experiment. For this reason only a twodimensional measurement with a hotfilm rheometer and the object position to the fish can be given. In each diagram the fish indicates object position and moving direction in relation to the $\mathrm{x}$-axis, which corresponds to one object revolution. The water particle movement was measured with a custom-made (P. Meyer) rheometer by monitoring the temperature of the rheometer wire, which is comparable to the system used by Coombs, Fay and Janssen (9). By keeping the wire at the same temperature, changes in heating power indicate the relative movement of surrounding water.

\section{RESULTS AND DISCUSSION}

The moving object used in this study is clearly a strong and non-uniform stimulus for the lateral line, which is in the same range as water movement caused by a swimming fish. Because the hair cells have very low thresholds, with values as low as 0.01 to $5 \mu \mathrm{m}$ p-p displacement, even unavoidable background noise in flowing water leads to an increased activity of spontaneously active afferents $(4,18,27)$. An object moving along the rostro-caudal axis of a fish is clearly a strong stimulus that lasts for seconds $(6,26)$. Although the moving object in this experiment works as a repetitive stimulus on a circular course (Fig. 1A), the generated stimuli are non-uniform. Moving at $20 \mathrm{~cm} / \mathrm{sec}, 10 \mathrm{~cm} / \mathrm{sec}$, or 2.3 $\mathrm{cm} / \mathrm{sec}$ at a distance of $2 \mathrm{~cm}$ from the fish, one should expect unpredictable distributions of local particle activity despite uniform movement of the stimulus object (Fig. 1B). These are caused by alternating eddies, which lead to complex hydrodynamic effects and are visible with the naked eye. The vortices behind the moving object did not show any visible regularity in their location but certain responding neurons did show almost identical responses to the moving object. This may indicate that, despite the variability of the water movement, some identical properties of the stimuli exist.

Previous recordings of lateral line nerves have shown that primary afferents are spontaneously active $(6,14)$. But, in the midbrain torus semicircularis, which contains at least third-order neurons of the lateral line system, resting activity is very low (mostly about 0 to $2 \mathrm{~Hz}$ ), and cells may react exclusively to certain components of the complex hydrodynamic stimulus. From 77 neurons recorded in the torus semicircularis of the midbrain, 40 had a mechanosensory lateral line input. Toral lateral line neurons were found that 

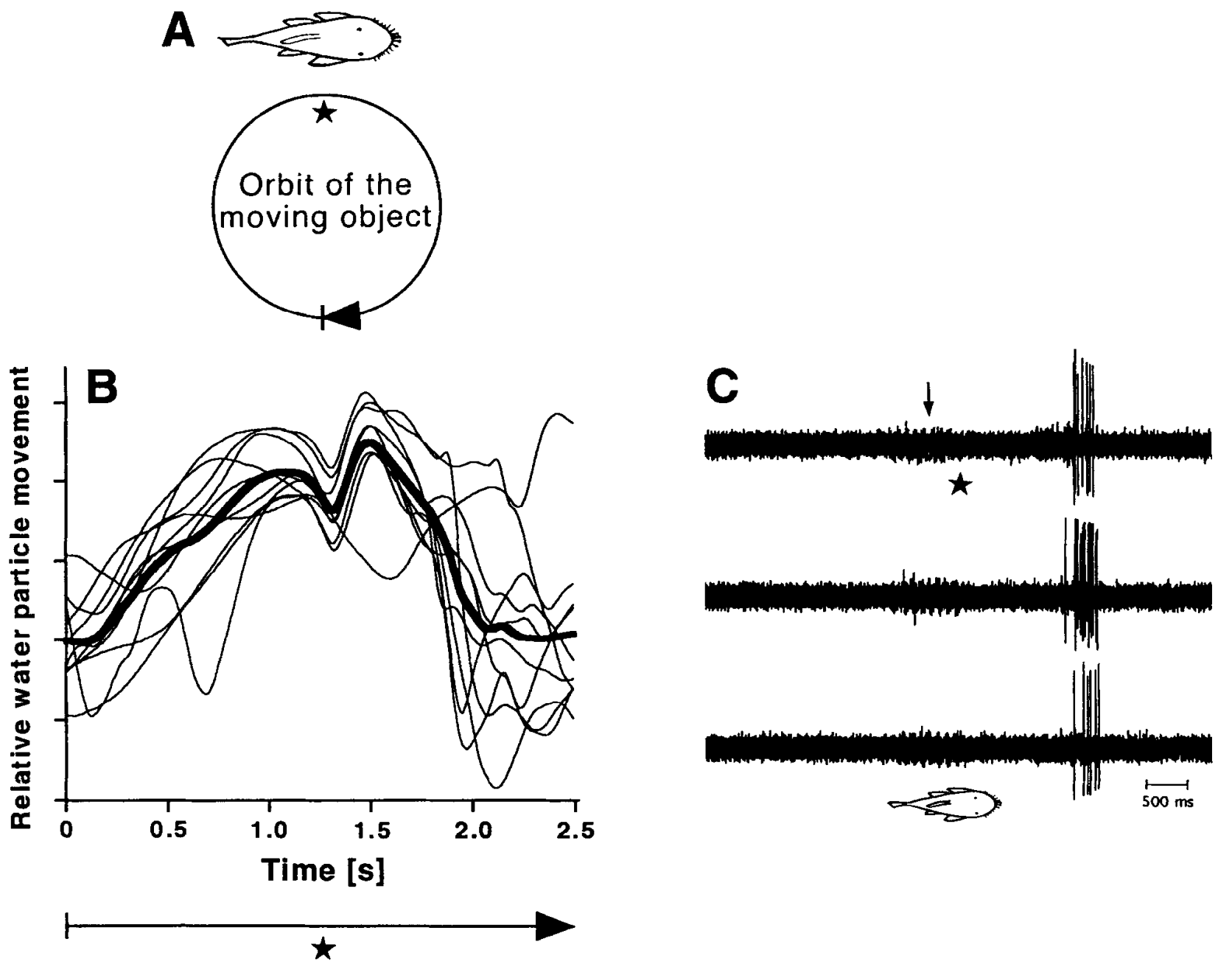

FIG. 1. A) Sketch of the relation between the fish size and moving object orbit. The asterisk corresponds to the position in Figures $B$ and C. B) Diagram of the water movement induced by the moving object, measured with a hotfilm rheometer in fish position. The induced water currents are shown for one revolution in posterior/anterior direction. Even this only twodimensional representation of water particle movement over time shows the enormous variability of such an apparently uniform stimulus, in addition to the disturbances caused by the actual shape of the fish body, which acts as an obstacle. Traces recording 10 revolutions of the moving object are shown, as well as their mean curve (bold line). The hydrodynamic stimulus of the moving object is most uniform when it is closest to the fish (asterisk), the amplitudes of the whirl patterns running before and after the object are unpredictable. C) Specificity to vortices: Action potentials of a toral neuron that reacts exclusively to the visible vortices following the moving object and to the complex water movement caused by it, independent of the object speed. The response to the medium object speed $(10 \mathrm{~cm} / \mathrm{sec})$ is shown. By the time the object itself passes the fish, only discharges of other neurons are visible as "hash" (arrow).

reacted exclusively to the complex water movement caused by the moving object (Fig. 1C). These response characteristics were typical for each neuron and were independent of the tested speed of the moving object. These neurons showed identical response patterns to object speeds of 20 , 10 and sometimes even $2.3 \mathrm{~cm} / \mathrm{sec}$, which shows that the response was related to the vortices and not merely a delayed response to the noving rod. The complex patterns of the vortices passing the fish body were clearly visible and the time between the rod and its trailing vortex was up to $2800 \mathrm{~ms}$. Even though the stimulus itself is still strong and non-uniform, a subset of neurons only show a response to the trailing vortices, i.e. a time-locked, short burst of activity. Only when the vortices reach the fish body did the response occur, at which time the object had long passed the fish (about 300,900 or $2800 \mathrm{~ms}$ ). Before that, at the time the object itself passed the fish, only discharges of other neurons are visible as so-called hash (Fig. 1C, arrow).

The tested 28 neurons could not be divided into specific groups in terms of preferred direction. However, a subset of neurons responded exclusively to a preferred direction of the moving object. For example, neuron No. 7 (posterior) 


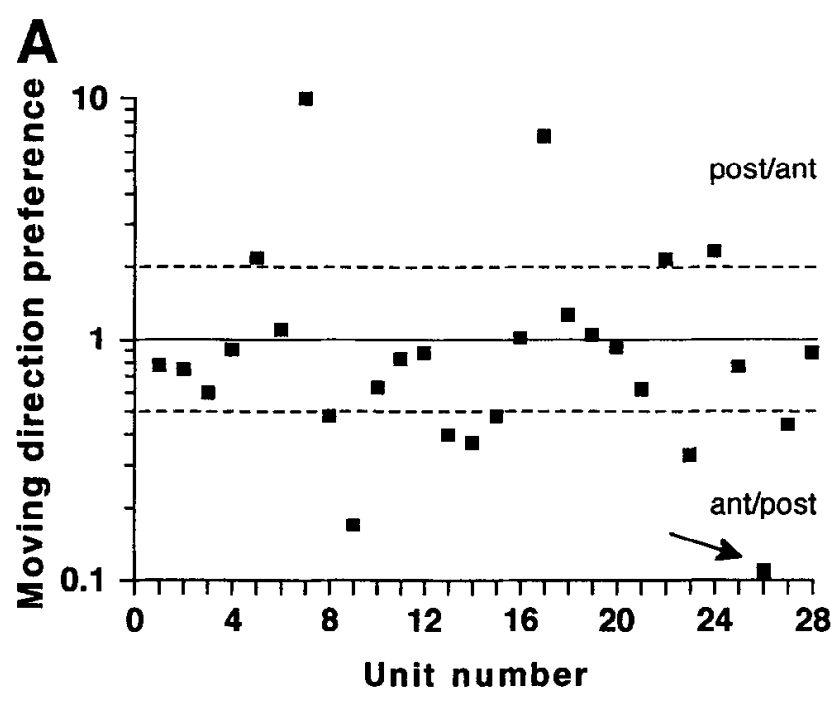

B

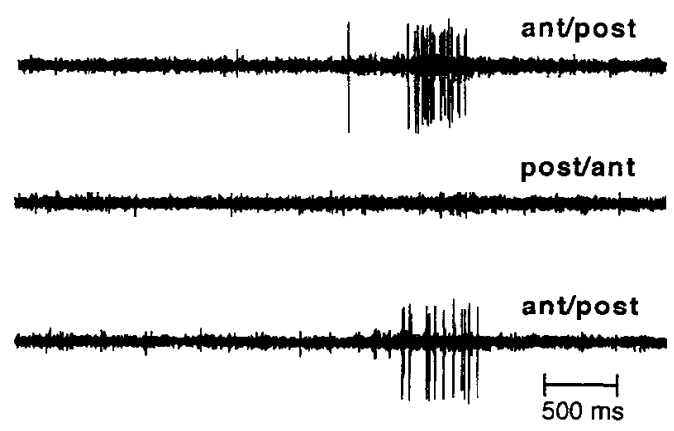

FIG. 2. Motion direction specificity of certain neurons: A) The relative direction preferences for moving objects of 28 tested toral neurons of the lateral line. Although most neurons do not have a preferred moving direction, some neurons are highly sensitive for the moving direction. Each point in the figure is a quotient of the maximal discharge rate for both directions of object movement. The solid line means no direction preference, while each dashed line represents a spike relation of $2: 1$ for each motion direction. B) Example of a neuron with extreme sensitivity for motion direction (neuron No. 26, arrow) that responded exclusively to the object moving from anterior to posterior.

anterior) and neuron No. 26 (anterior/posterior) in Figure $2 \mathrm{~A}$. While single hair cells and neuromasts do have a certain directionality, until now there had been no evidence for a topographic projection for directionality in fish. In addition, recordings from primary fibers don't show a movement directionality (6). Nevertheless, on the midbrain level, some units respond very sensitively only to the preferred direction of a moving object.

Three of nine bilateral sensitive neurons responded only to a contralateral sphere-stimulus, not to simultaneously bilateral stimulation, independent of the stimulus intensity (Fig. 3). During simultaneous stimulation on both sides of the fish the contralateral stimulus was no longer responded to by these neurons. This test was conducted while the spheres oscillated in and out of phase, at different locations to the fish body and with amplitudes up to $10 \mathrm{~mm}$. These response characteristics during stimulation with bilateral oscillating spheres may be important for eliminating self-induced water movement and show similarities to the noise cancellation (common mode rejection) in the electrosensory system of the thomback ray $(21,22)$ and to the inhibition of lateral line input during the startle response in goldfish (32).

A further indication of the stimulus specificity of a subset of toral neurons $(n=5)$ follows from the observation that sinusoidally oscillating spheres $(50-200 \mathrm{~Hz})$, which were placed in different positions on the fishes' body length axis, triggered no responses in the tested amplitude range of 15 $\mathrm{dB}$, but the moving object stimulus did. This shows that more natural and complex hydrodynamic stimuli are essential for examining the lateral line information processing in the central nervous system, at least at the midbrain level.

Other than neurons, which react to the moving object with a long-lasting increasing and decreasing response ( $n$ $=8$ ), five neurons did show a short phase of response inhibition before the response maximum. Furthermore, two neurons showed an inhibition before and after the response maximum. As shown in Figure 4, such a response behavior points to the existence of receptive fields of toral lateral line neurons, strongly reminding one of OFF-center behavior of visual units. Other units have shown an $\mathrm{ON}$-center behavior (25). This response characteristic has not heen reported

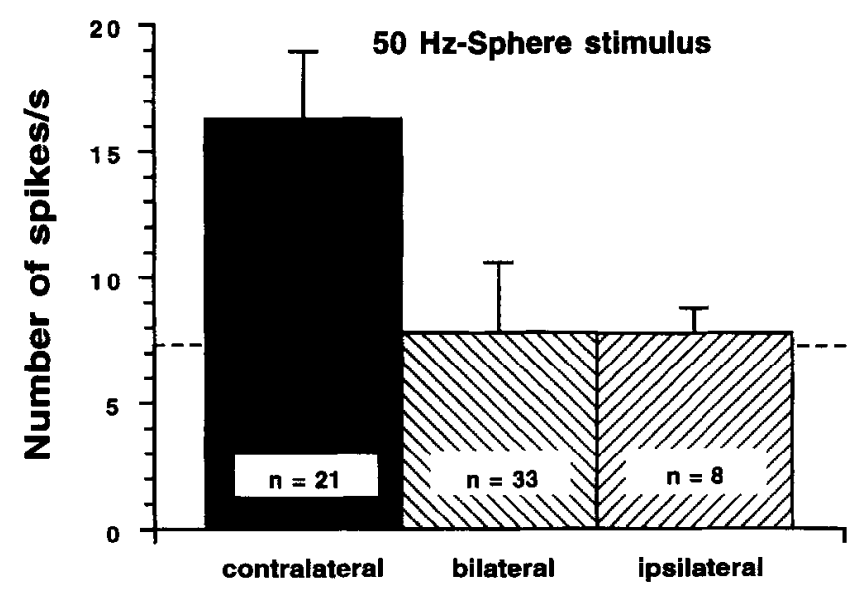

FIG. 3. Inhibition caused by bilateral stimulation: Inhibition of the contralateral response of a neuron while simultaneously stimulated on both sides of the fish body through laterally fixed, sinusoidally oscillating spheres $(50 \mathrm{~Hz})$. The bar diagram shows the average discharge rate per second and standard deviation for a total of 62 trials, including contralateral, bilateral and ipsilateral stimuli. The dashed line shows the resting activity. In the tested range of the oscillation amplitude $(17 \mathrm{~dB})$, the detection inhibition was independent of the amplitude, the phase or the location of the spheres. 

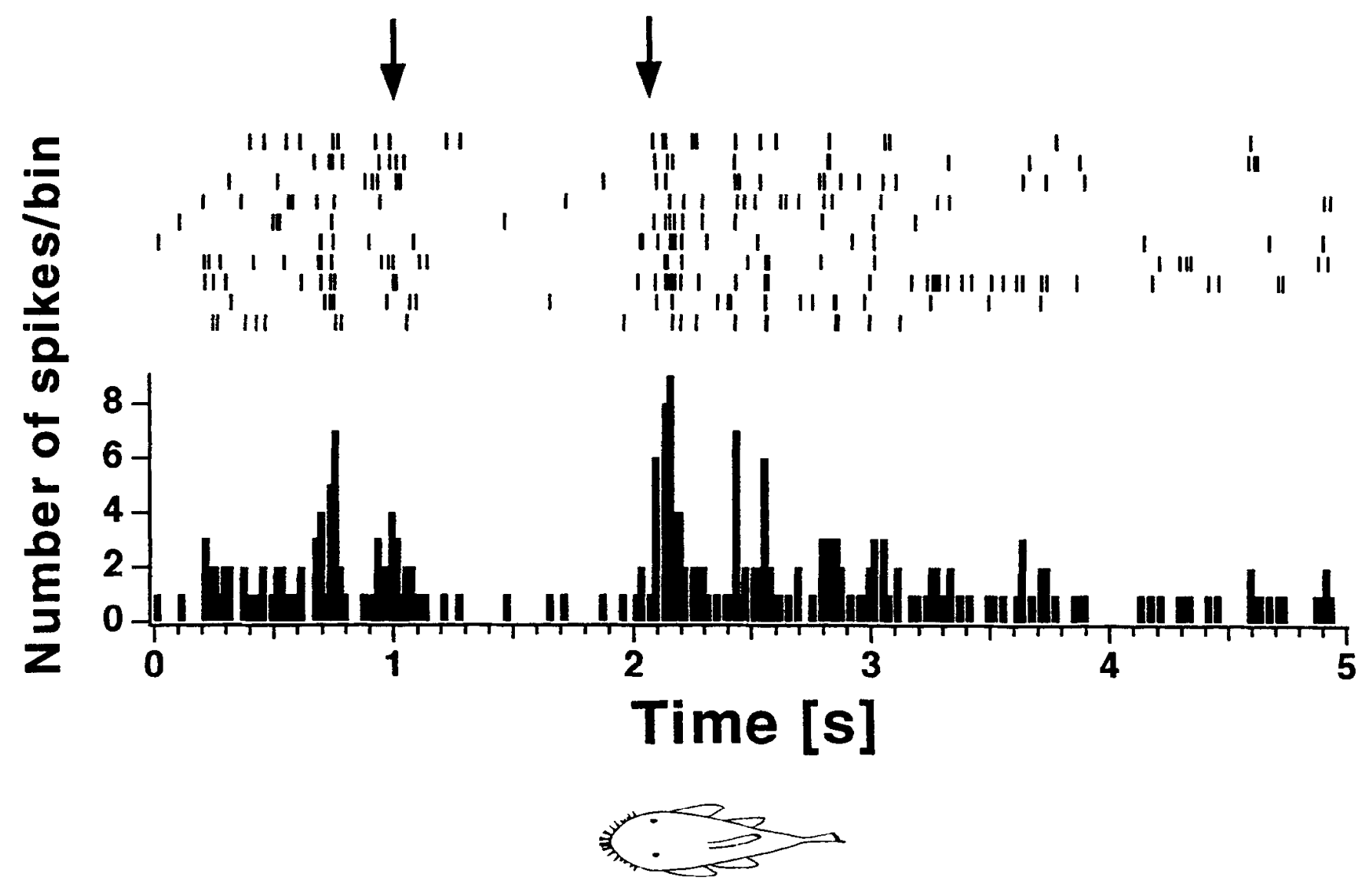

FIG. 4. OFF-center neuron: Example of ten responses of a toral neuron to object movements of $10 \mathrm{~cm} / \mathrm{sec}$ (anterior/posterior) are represented in a line display. Each line represents a single action potential, each row of lines one revolution of the stimulus. The histogram of frequency is given (class width $20 \mathrm{~ms}$ ) below the diagram. The scaled fish indicates the closest object position. This type of response with a centered inhibition lets us assume that the object crossed a receptive field with an OFF-center (arrows).

for lateral line neurons, so far. Testing the receptive field dimensions with water jets and a tuft of hairs yielded sizes of half or whole body length, mostly from the mouth up to a point behind the pelvic fin. Unfortunately almost nothing is known about the distribution and anatomy of the peripheral receptors in Ancistrus, until now. In addition to lateral line cells showing an ON/OFF-center like response behavior, there is also evidence for complex himodal filters in the torus; e.g., mechano- and electrosensitive as well as visual and electrosensitive units, functioning analogous to the technical AND-, OR-, and NAND-gates (25). This relates to earlier findings on bimodal units in trout $(28,34)$ indicating that complex neuronal filters in lateral line processing exist as early as in third order neurons in the torus semicircularis.

In addition to possessing well-developed olfactory and hearing senses, Ancistrus has both a mechanosensory lateral line and an electrosensory lateral line (the ampullary organs). Although endowed with several discriminating sensory organs, Ancistrus is not highly specialized, so the present findings are likely to extend to other bony fish as well. No sex-related differences in lateral-line processing could be observed. The lateral line does not function solely in the registering of simple laminar flow but also in the perception of complex hydrodynamic events involved in schooling behavior (29), predation $(2,24)$, intra-species communication $(13,33)$, and general orientation $(8)$. The response hehavior of toral lateral-line neurons seems to show complex filter properties, which reminds one of feature detectors in other sensory systems as in the visual (15) and the acoustic system (16). Presumably, these neurons perform spatial and temporal analyses of complex hydrodynamic events, which afford an internal representation of the environment, as assumed previously by Dijkgraaf (12) and Kuiper (18). Results from oceanographic research show that hydrodynamic events are not necessarily short-lived. Oceanic internal and surface waves can be traced far back in time by satellite cameras and are used for tactical purposes (20). Also, small ships generate whirl tracks more than 40 kilometers in length, which are clearly visible from 
space and may allow a speed and directional analysis for hours (1). Fish, likewise, generate complex :vhirl tracks by their swimming movements $(4,18)$, and these may remain constant for several minutes or longer and can be perceived as whirl tracks by other fish. Showing responses of toral neurons, which react only to complex stimuli, this study provides electrophysiological evidence that bony fish perceive complex hydrodynamic events. However, this study also showed that it is very difficult to control such complex hydrodynamic stimuli in an experiment. Further experiments have to be carried out in order to gain a more analytical insight into the physical properties of the stimuli. Furthermore, in future experiments real fish showing a startle response nearby for example could be used for stimulating the lateral line, which would deliver even more complex and perhaps non-uniform but really natural stimuli.

I am indebted to Dr. H. Bleckmann for introducing me to the field of lateral line research and for his valuable support. My thanks also go to Drs. J. King, M. Kutas, T. H. Bullock, B. Claas and three anonymous referees for their helpful comments on a previous version of the manuscript and Ms. G. Delany for improving the English. This research was sponsored by a grant from the German Science Foundation (DFG) to H. Bleckmann.

\section{References}

1. Apel, J.R.; Byrne, H.M.; Proni, J.R.; Charnell, R.L.J. Observations of oceanic internal and surface waves from the earth resources technology satellite. Geophys. Res. 80:865-881; 1975.

2. Bleckmann, $H$. Reaction time and stimulus frequency in prey localization in the surface-feeding fish Aplocheilus lineatus. J. Comp. Physiol. 140A:163-172;1980.

3. Bleckmann, H. Reception of Hydrodynamic Stimuli in Aquatic and Semiaquatic Animals. Stuttgart: Fischer Verlag; 1994.

4. Bleckmann, H.; Breithaupt, T.; Blickhan, R.; Tautz, J. The time course and frequency content of hydrodynamic events caused by moving fish, frogs, and crustaceans. J. Comp. Physiol. 168A:749-757;1991.

5. Bleckmann, H.; Bullock, T.H.; Jørgensen, M. The lateral line mechanoreceptive mesencephalic, diencephalic, and telencephalic regions in the thornback ray, Platyrhinoidis triseriata (Elasmobranchii). J. Comp. Physiol. 161A:67-84;1987.

6. Bleckmann, H.; Zelick, R. The responses of peripheral and central mechanosensory lateral line units of weakly electric fish to moving objects. J. Comp. Physiol. 172:115-128; 1993.

7. Bullock, T.H.; Helligenberg, W. (eds). Electroreception. New York: Wiley; 1986.

8. Campenhausen, C.v.; Riess, I.; Weissert, R. Detection of stationary objects in the blind cave fish Anoptichthys jordani (Characidae). J. Comp. Physiol. 143A:369-374;1981.

9. Coombs, S.; Fay, R.R.; Janssen, J. Hot-film anemometry for measuring lateral line stimuli. J. Acoust. Soc. Am. 85:21852193;1989.

10. Coombs, S.; Görner, P.; Münz, H. (eds). The Mechanosensory Lateral Line: Neurobiology and Evolution. Springer; 1989.

11. Coombs, S.; Janssen, J. Behavioral and neurophysiological as- sessment of lateral line sensitivity in the mottled sculpin, Cottus bairdi. J. Comp. Physiol. 167A:557-567;1990.

12. Dijkgraaf, $S$. The functioning and significance of the lateral line organs. Biol. Rev. 38:51-106:1963.

13. Gray, J.A.R.; Denton, E.J. Fast pressure pulses and communication between fish. J. Mar. Bio. Ass. UK 71:83-106;1991.

14. Harris, G.G.; Bergeijk, W.A.v. Evidence that the lateral-line organ responds to near-field displacements of sound sources in water. J. Acoust. Soc. Am. 34:1831-1841;1962.

15. Hubel, D.H. Eye, Brain, and Vision. New York: Scientific American; 1988.

16. Keidel, W.D.; Kallert, S.; Korth, M. The Physiological Basis of Hearing: A Review. Stuttgart: Thieme-Stratton; 1983.

17. Kroese, A.B.; Schellart, N.A.M. Velocity- and accelerationsensitive units in the trunk lateral line of the trout. J. Neurophysiol. 68:2212-2221;1992.

18. Kuiper, J.W. Frequency characteristics and functional signifcance of the lateral line organ. In: Cahn, P.H. (ed). Lateral Line Detectors. Bloomington: Indiana University Press; 1987: $105-121$.

19. Lettvin, J.Y.; Maturana, H.R.; McCulloch, W.S.; Pitts, W.H. What the frog's eye tells the frog's brain. Proceedings of the Institute of Radio Engineers. 47:1940-1951;1959.

20. Malay, J.T. Tactical oceanography from space: the next decade. In: AGARD Conference Proceedings, No. 460, Tactical Applications of Space Systems. 1990:11-14.

21. Montgomery, J.C. Noise cancellation in the electrosensory system of the thornback ray; common mode rejection of input produced by the animals' own ventilatory movement. J. Comp. Physiol. 155A:103-111;1984.

22. Montgomery, J.C.; Bodznick, D. An adaptive filter that cancels self-induced noise in the electrosensory and lateral line mechanosensory systems of fish. Neurosci. Lett. 174:145-148; 1994.

23. Montgomery, J.C.; Coombs, S. Physiological characterization of lateral line function in the Antarctic fish Trematomus bernacchii. Brain Behav. Evol. 40:209-216;1992.

24. Montgomery, J.C.; Macdonald, J.A. Sensory tuning of lateral line receptors in Antarctic fish to the movements of planktonic prey. Science 235:195-196;1987.

25. Müller, H.M. Neuronale Verarbeitung von Seitenlinieninformationen im Mittelhirn eines Welses. Münster: Waxmann Verlag. (PhD thesis, University of Bielefeld).

26. Müller, H.M.; Bleckmann, H. Responses of midbrain lateral line units to moving objects in a catfish. In: Elsner, N.; Ruth, G. (eds). Proceedings of the 18th Göttingen Neurobiology Conference. Stuttgart: Thieme; 1990:169.

27. Münz, H. Single unit activity in the peripheral lateral line system of the cichlid fish Sarotherodon niloticus L. J. Comp. Physiol. 157A:555-568;1985.

28. Nederstigt, L.J.A.; de Heij, C.; Schellart, N.A.M. Characteristics of auditory and lateral line responses in the torus semicircularis of the trout (Salmo gairdneri). Neurosci. Lett. (Suppl.) 18:S242:1984.

29. Pitcher, T. Sensory information and the organization of behaviour in a shoaling fish. Anim. Behav. 27:126-149;1979.

30. Platt, C.; Popper, A.N.; Fay, R.R. The ear as part of the octavolateralis system. In: Coombs, S.; Görner, P; Münz, H. (eds). The Mechanosensory Lateral Line: Neurobiology and Evolution. New York: Springer; 1989:633-651.

31. Pollack, G.D.; Casseday, J.H. The Neural Basis of Echolucation in Bats. Berlin: Springer Verlag; 1989.

32. Russell, I.J.; Central and peripheral inhibition of lateral line input during the startle response in goldfish. Brain Res. 80: $517-522 ; 1974$. 
33. Satou, M.; Takeuchi, H.-A.; Nishii, J.; Tanabe, M.; Kitamura, S.; Okumoto, N.; Iwata, M. Behavioral and electrophysiological evidences that the lateral line is involved in the intersexual vibrational communication of the hime salmon (Landlocked Red Salmon, Oncorhynchus nerka). J. Comp. Physiol. 174A:539-549;1994.

34. Schellart, N.A.M. Acousticolateral and visual processing and their interaction in the torus semicircularis of the trout, Salmo gairdneri. Neurosci. Lett. 42:39-44:1983.

35. Wubbels, R.J.; Kroese, A.B.A.; Schellart, N.A.M. Response properties of lateral line and auditory units in the medulla oblongata of the rainbow trout (Oncorhynchus mykiss). J. Exp. Biol. 179:77-92;1993. 